\title{
A CASE REPORT OF DUODENAL GANGLIOCYTIC PARAGANGLIOMA - IS DUODENOPANCREATECTOMY NECESSARY?
}

\author{
Antonio Serafin Valero-Liñán, \\ José Ignacio Miota de Llama, \\ José Antonio Gonzalez-Masiá, \\ Toni I. Stoyanov, Belén Conde- \\ Inarejos, \\ Olga Luengo-Ballester, \\ Cristina Camacho-Dorado, \\ Alba Sanchez-Gallego, \\ Beatriz Aguado-Rodríguez, \\ Kaloyan T. Ivanov1, \\ Pencho T. Tonchev ${ }^{2}$ \\ Department of General and Digestive \\ Surgery, \\ Albacete University Hospital Complex, \\ Spain \\ 1 Department of General and Plastic \\ Surgery, \\ University Hospital "Medika”, Ruse, \\ Bulgaria \\ 2Department of Surgical Propaedeutics, \\ Medical University - Pleven, \\ Bulgaria
}

\begin{abstract}
Summary
Gangliocytic paraganglioma (GP) is an uncommon finding in the periampullary region of the duodenum. In the Department of General and Digestive Surgery of the Albacete University Hospital Complex, a 45-years-old patient was diagnosed with a $17 \times 13 \mathrm{~mm}$ hypervascular nodular lesion in the descending part of the duodenum during an examination for hepatic hemangiomas. Ampullectomy was performed, followed by a favourable postoperative period. Histological analysis proved GP. There were no involvement of lymph nodes and a malignancy potential, so the clinical and radiological follow-up opted. In conclusion, because such tumours have unpredictable behavior, we recommend local resection of the tumour, except in cases in which local or ganglionic progression is suspected or confirmed, and thus cephalic pancreaticoduodenectomy (CPD) and lymphadenectomy are suggested.
\end{abstract}

Key words: gangliocytic paraganglioma, duodenum, periampullary region, ampullectomy, lymph nodes

\section{Introduction}

Gangliocytic paraganglioma (GP) is a rare finding in the periampullary region of the duodenum [1]. It is characterized by triple cellular differentiation (epidermoid neuroendocrine cells, spindle-shaped Schwann cells, and ganglion cells), reported by Dahl et al. (1957) as duodenal ganglioneuroma [2]. The term GP was adopted by Kepes et Zacharias (1971) [3].

\section{The case description}

A 45-year-old patient was admitted with a history of right hemithyroidectomy and a histological result of nodular hyperplasia. The patient affirmed penicillin and streptomycin allergy and arterial hypertension under medical treatment, and no family history of interest.

One year later, after the removal of a bone lesion in the right femur compatible with bone metastasis due to papillary adenocarcinoma of thyroid or ovarian origin, ovarian pathology was ruled out, and total thyroidectomy was performed to allow the use of thyroglobulin as a tumour marker (being reported as healthy thyroid tissue). After the intervention, body scan revealed a positive result, so treatment with

Corresponding Author:
Antonio Serafin V. Liñán
Department of General and Digestive
Surgery,
Albacete University Hospital Complex
37, C/ Hermanos Falco Str.
Albacete, 02006
Spain
e-mail: aseravl@yahoo.es
Received: April 21, 2019
Revision received: May 20, 2019
Accepted: July 30, 2019

Corresponding Author:
Antonio Serafin V. Liñán
Department of General and Digestive
Surgery,
Albacete University Hospital Complex
37, C/ Hermanos Falco Str.
Albacete, 02006
Spain
e-mail: aseravl@yahoo.es
Received: April 21, 2019
Revision received: May 20, 2019
Accepted: July 30, 2019

Corresponding Author:
Antonio Serafin V. Liñán
Department of General and Digestive
Surgery,
Albacete University Hospital Complex
37, C/ Hermanos Falco Str.
Albacete, O2006
Spain
e-mail: aseravl@yahoo.es
Received: April 21, 2019
Revision received: May 20, 2019
Accepted: July 30, 2019 
radioactive Iodine 131 was administered.

During the subsequent six years, the routine annual clinical examinations were performed (computerized tomography or CT scans for short, tumour markers, etc.) without evidence of tumour recurrences. A follow-up magnetic resonance imaging (MRI) scan at the Gastroenterology and Hepatology Department for hepatic hemangiomas revealed an asymptomatic hypervascular nodular lesion sized 17 x 13 $\mathrm{mm}$ in the second duodenal portion. The MRI findings were compatible with a solid duodenal tumour similar to a neuroendocrine tumour.

Endoscopic ultrasound was performed

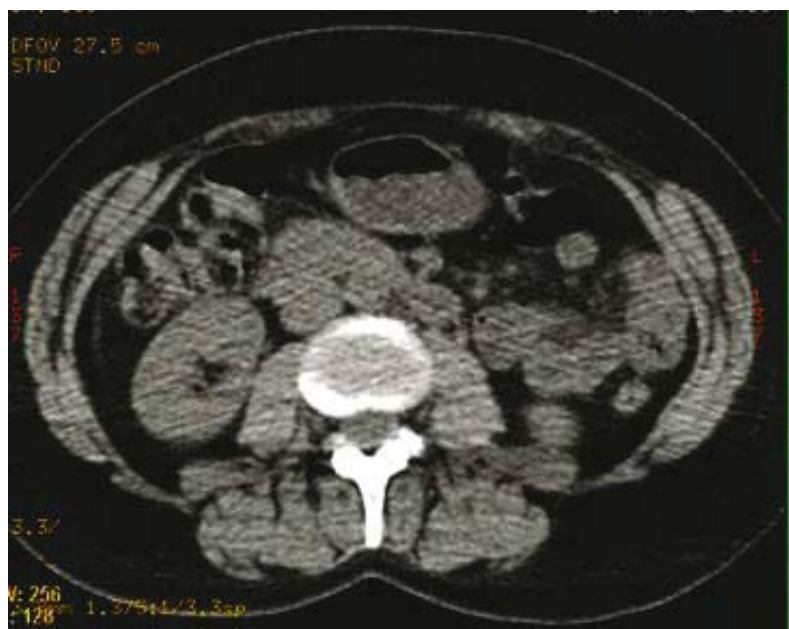

Figure 1. Duodenal tumour

The abdominal examination elicited a marked increase in metabolic activity at the left pelvic level that could correspond to ovarian activity. with fine-needle biopsy, finding a hypoechoic submucosal duodenal tilting lesion of $11 \times 18$ $\mathrm{mm}$ with well-defined periampullary walls, without expressed adenopathies. No pathologies disorders were found in the pancreas and Wirsung's channel. The histopathological examination proved the presence of malignant tumour cells, suggestive of poorly differentiated carcinoma. Positron Emission Tomography (PET) scan was requested, which revealed a duodenal nodular lesion with a SUVmax of 6.4 and a metabolic diameter of approximately $18 \mathrm{~mm}$ of destructive metabolic behaviour (Figure1).

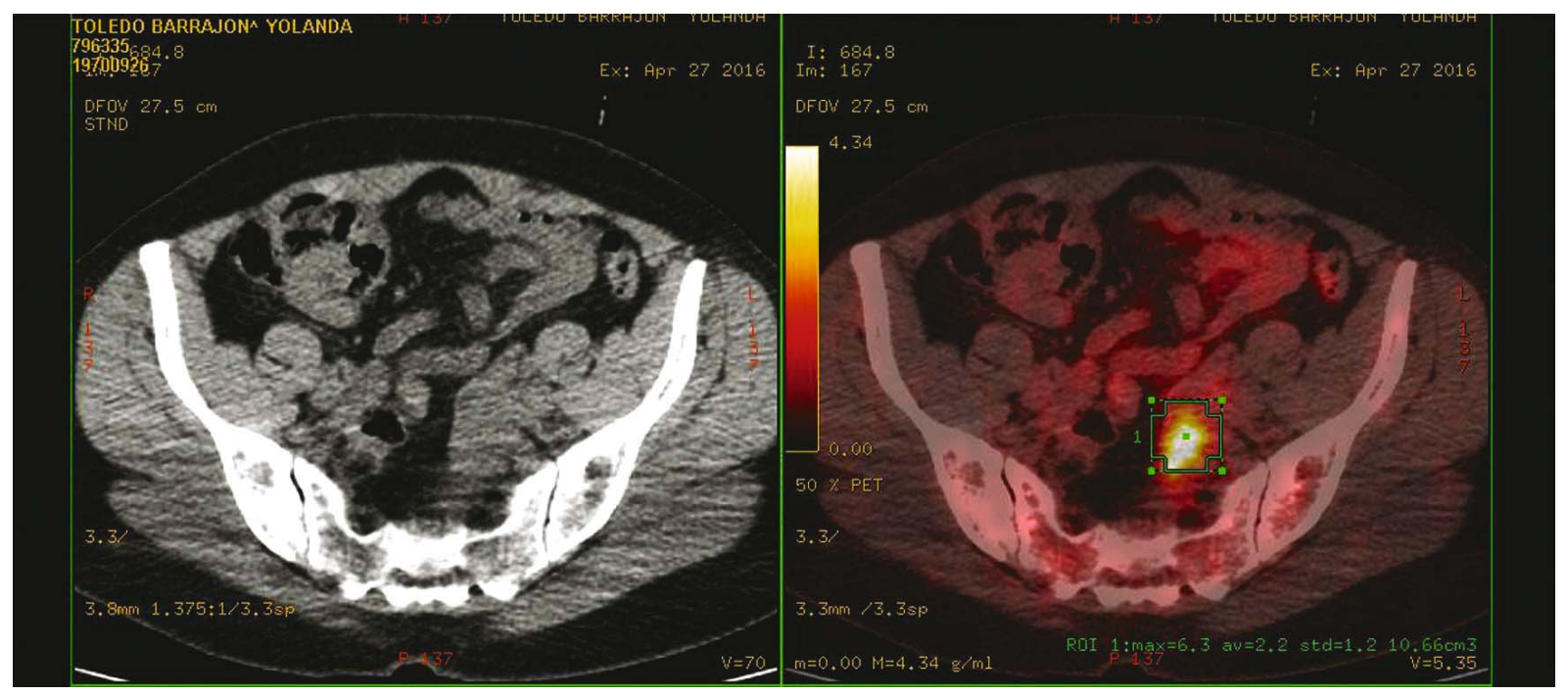

Figure 2. Pelvic tumour

Gynaecological assessment (SUVmax-6.3) was recommended to rule out malignancy at this level (Figure 2).

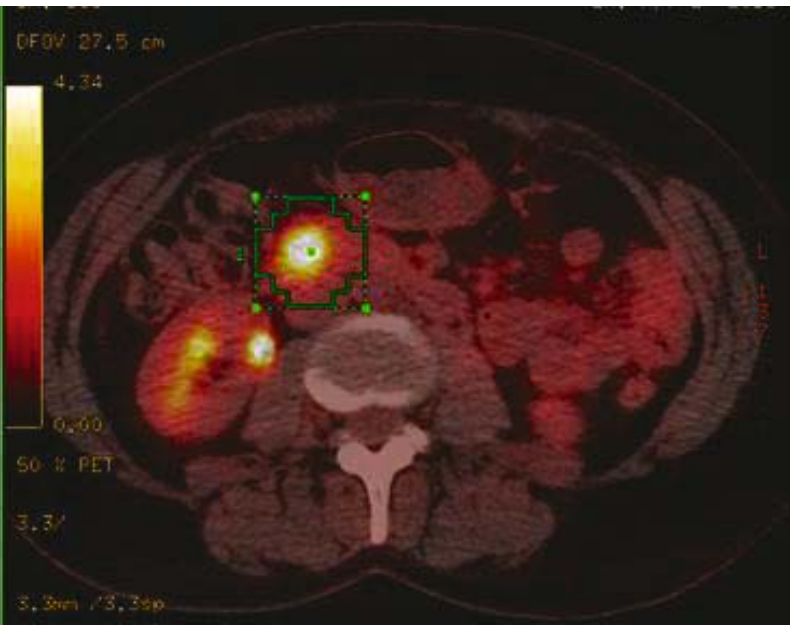


With the suspected diagnosis of malignant duodenal periampullary lesion (ampuloma vs neuroendocrine tumour vs duodenal carcinoma vs paraganglioma), the patient underwent elective surgery, finding a periampullary submucosal tumour less than $2 \mathrm{~cm}$ in diameter, pedunculated intercavoaortic adenopathies, and enlargement of the left adnexa. Given the findings, cholecystectomy was performed with papilla catheterization, duodenotomy, ampullectomy, left adnexectomy and intercaval aortic lymphadenectomy. The postoperative period was uneventful, and the patient was discharged on the fifth postoperative day. The histological result was GP with clear surgical margins, and with no lymph node involvement. The left adnexa showed no evidence of malignancy.

Recently, three years after the surgery, the patient was asymptomatic with a clear clinical and radiological follow up.

After local surgical resection with free margins and no lymph node involvement, the size being less than $2 \mathrm{~cm}$ and without exceeding the submucosa in a middle-aged patient, we debated whether to complement the treatment with a cephalic pancreaticoduodenectomy (CPD) or, on the contrary, to perform a postoperative followup. The case was presented to the Hepato-BilioPancreatic Committee of tumours in the hospital, and we opted, along with the patient, for a strict clinical and radiological follow-up. After two years of follow-up through imaging and endoscopy, the patient remains asymptomatic and free of disease.

\section{Discussion}

The GPs are rare tumours usually located in the periampullary region of the duodenum. Because of this and their tendency to ulcerate, these lesions typically manifest with abdominal pain, upper gastrointestinal bleeding, anaemia, or obstructive jaundice. They are often asymptomatic and diagnosed incidentally during endoscopic or radiological studies for other causes, as it was in our case [4]. It is difficult to make a histological diagnosis employing endoscopic biopsy due to its submucosal location, and resection of the lesion is usually required to establish a definitive diagnosis [5]. Histological diagnosis highlights the presence of three distinct cell types: neuroendocrine epidermoid cells, spindleshaped Schwann cells and ganglion cells.

Historically, the GP was considered benign, and simple excision was, therefore, the treatment of choice [5, 6]. Recently there have been opposing publications of patients with recurrence, lymphadenopathy and distant metastasis, which reveal their potential for malignancy $[7,8]$. The characteristics of the tumour or the clinical case that should make us suspect such possibility are size greater than $2 \mathrm{~cm}$ [9], young age, and tumours that infiltrate beyond the submucosa layer [10]. It seems that these last two factors are more important than tumour size as predictors of malignancy. Despite the considerations as mentioned above, the treatment of GP remains highly controversial. Some authors recommend performing a CPD with lymphadenectomy [1], and some even advocate postoperative adjuvant radiotherapy [11]. However, these procedures are associated with significant morbidity and mortality, and the vast majority of GPs have benign behaviour. Nevertheless, it is still recommended to perform total resection of the local lesion [12], either endoscopically or surgically [13]. The criteria proposed by the American Society of Gastrointestinal Endoscopy (SAGES) for endoscopic excision are size under $5 \mathrm{~cm}$, no macroscopic or histological signs of malignancy, and no ductal invasion or one that is less than $1 \mathrm{~cm} \mathrm{[7].}$

\section{Conclusions}

GP is uncommon, often asymptomatic, and is a diagnostic challenge, whose optimal treatment is still under discussion. Given its uncertain behaviour due to its malignant potential, local resection of the tumour is recommended. However, in cases, in which local or ganglion progression is suspected or confirmed, CPD and lymphadenectomy are recommendable.

\section{Acknowledgements}

The authors declare there are no conflicts of interest and financial sources for this article. 


\section{References}

1. Witkiewicz A, Galler A, Yeo CJ, Gross SD. Gangliocytic paraganglioma: case report and review of the literature. J Gastrointest Surg. 2007;11(10):1351-4

2. DahlEV, Waugh JM, Dahlin DC. Gastrointestinal ganglioneuromas; brief review with report of a duodenal ganglioneuroma. Am J Pathol. 1957;33(5):953-65.

3. Kepes JJ, Zacharias DL. Gangliocytic paragangliomas of the duodenum. A report of two cases with light and electron microscopic examination. Cancer. 1971;27(1):61-7.

4. Yang M, Leighton JA, Faigel DO, Katariya NN. Duodenal gangliocytic paraganglioma: endoscopy, sonography and F-18 FDG PET/CT imaging. Dig Liver Dis. 2017;49(10):1162.

5. Weijian $H$, Shengqiang $G$, Dongdong $C$, Lidong H, Ruijie D, Yunfeng S, et al. Duodenal gangliocytic paraganglioma with lymph node metastases: a case report and review of literature. Int J Clin Exp Pathol 2016;9(4):4756-60.

6. Scheithauer BW, Nora FE, LeChago J, Wick MR, Crawford BG, Weiland LH, et al. Duodenal gangliocytic paraganglioma. Clinicopathologic and immunocytochemical study of 11 cases. Am J Clin Pathol. 1986;86(5):559-65.

7. Palomino-Martínez BD, Espino-Cortés $\mathrm{H}$, Cerna-Cardona J, Godínez-Martínez LE, Chávez-García MA. [Duodenal gangliocytic paraganglioma: Treatment through endoscopic resection]. Rev Gastroenterol Méx. 2018;83(2):198-9. Spanish.
8. Okubo Y, Yoshioka E, Suzuki M, Washimi K, Kawachi K, Kameda Y, et al. Diagnosis, pathological findings, and clinical management of gangliocytic paraganglioma: a systematic review. Front Oncol. 2018;8:291.

9. Cappella C, Arnold R, Klimstra DS, Klöppel G, Solcia E, Rindi G, et al. Neuroendocrine neoplasms of the small intestine. In: Bosman FT, Carneiro F, Hruban RH, Theise ND, editors. WHO classification of tumours of the digestive system. $4^{\text {th }}$ edition. France: IARC Press; 2010. p. 102-7.

10. Okubo Y, Wakayama M, Nemoto T, Kitahara K, Nakayama H, Shibuya K, et al. Literature survey on epidemiology and pathology of gangliocytic paraganglioma. BMC Cancer. 2011;11:PMC3141762.

11. Wong A, Miller AR, Metter J, Thomas CR. Locally advanced duodenal gangliocytic paraganglioma treated with adjuvant radiation therapy: case report and review of the literature. World J Surg Oncol. 2005;3(1):15.

12. Narang V, Behl N, Sood N, Puri H. Gangliocytic paraganglioma of duodenum. Case Rep Pathol. 2013:378582.

13. Adams L, Friedman TM, Shaver TR, Younan G. Duodenal gangliocytic paraganglioma requiring a pancreaticoduodenectomy: a case report and review of the literature. Case Rep Surg. 2018:6292789. 